\title{
Brazilian Journal

\section{SHELF LIFE OF FRESH-CUT SPINACH AS AFFECTED BY CHEMICAL TREATMENT AND TYPE OF PACKAGING FILM}

\author{
A.M.Piagentini* and D.R.Güemes \\ Instituto de Tecnología de Alimentos, Facultad de Ingeniería Química, \\ Universidad Nacional del Litoral, C.C. 266 - 3000 Santa Fe - Argentina \\ E-mail: ampiagen@fiqus.unl.edu.ar
}

(Received March 5, 2002 ; Accepted, June 13, 2002)

\begin{abstract}
Fresh-cut vegetables are an important and rapidly developing class of convenience foods. Their storage life may be greatly reduced due to their high rates of respiration and transpiration and the possibility of enzymatic and microbiological deterioration. Consequently, the objective of this work was to determine the shelf life and the failure attribute that conditioned the shelf life of fresh-cut spinach treated with chemical solutions and packaged in bags with different permeabilities. The shelf life of fresh-cut vegetables was defined as the time of refrigerated storage at which any one of the sensory attributes scored below 7 or when the microbiological counts exceeded $5.10^{7} \mathrm{CFU} / \mathrm{g}$. Fresh-cut spinach was treated with citric acid and ascorbic acid solutions and packaged in mono-oriented polypropylene (OPP) bags or low-density polyethylene (LDPE) bags. Sensory attributes and total microbial counts were evaluated throughout refrigerated storage. Response surface methodology (RSM) was used to study the simultaneous effect of chemical treatment and refrigerated storage time on sensory and microbiological quality of fresh-cut spinach. A quadratic polynomial regression model was assumed for predicting off-odor, general appearance, wilting, browning, color, and mesophilic aerobic population. Type of packaging film only influenced development of off-odor $(\mathrm{p} \leq 0.001)$ and had no effect on visual sensory attributes or microbiological counts $(\mathrm{p}>0.05)$. Development of off-odor was the attribute that limited shelf life of fresh-cut spinach packaged in OPP bags. On the other hand, shelf life of samples packaged in LDPE bags was dependent on a decrease in general appearance or an increase in microbiological counts, depending on the chemical treatment used.
\end{abstract}

Keywords: shelf life, fresh-cut vegetables, packaging, spinach.

\section{INTRODUCTION}

Fresh-cut vegetables are an important and rapidly developing class of convenience foods. The suitability of these products is based on their attributes of convenience and fresh-like quality. A problem faced by these products is that their storage life may be greatly reduced as compared with the unprocessed raw material from which they are made. This problem may be due to their high rates of respiration and transpiration and the possibility of enzymatic and microbiological deterioration
(Huxsoll and Bolin, 1989). Therefore, spoilage of fresh-cut vegetables may result from degradation of sensory characteristics (color, texture, flavor, or aroma) as well as from microbiological degradation.

Of the methods available for controlling or moderating these degradative processes, packaging technology is vitally important. In particular, utilization of permeable polymeric films moderates moisture loss, retards the onset of product senescence and reduces the rate of sensory quality degradation by affecting the concentration of gases and water vapor within the package (Schlimme and

*To whom correspondence should be addressed 
Rooney, 1994). However, improperly modified atmospheric conditions may adversely affect product quality. Therefore, selection of suitable packaging materials is critical to obtaining the environment desired for extending the shelf life of fresh-cut vegetables.

Chemical treatments are also used on lightly processed fresh produce mainly for controlling decay, reducing browning and retaining firmness (Brecht, 1995). Low-pH organic acid solutions are used as antimicrobials to control bacteria or as antioxidants to prevent browning; to reduce discoloration of pigments; and to protect against loss of flavor, changes in texture, and loss of nutritional quality (Wiley, 1994). Chemical treatments with citric acid and/or ascorbic acid solutions prevent browning in fresh prepared potatoes (Langdon, 1987) and lettuce (Castañer et al., 1996). Unfortunately, products that are artificially acidified to $\mathrm{pH}$ levels of 3.5-4 lose their fresh-like quality (Huxsoll and Bolin, 1989).

Consequently, the objective of this work was to determine the shelf life and the failure attribute that conditioned the shelf life of fresh-cut spinach treated with chemical solutions and packaged in bags with different permeabilities.

\section{MATERIAL AND METHODS}

\section{Experimental Design}

Response surface methodology (RSM) was used to study the simultaneous effect of chemical treatment and refrigerated storage time on fresh-cut spinach. The experiments were based on a threelevel, three-factor factorial design, with two replicates at the central point (Montgomery, 1991). It was assumed that a mathematical function exists for each response variable $\mathrm{Y}_{\mathrm{k}}$ (off-odor, general appearance, wilting, browning, color, and mesophilic aerobic population) in terms of three independent variables: citric acid concentration $\left(\mathrm{c}_{\mathrm{C}}\right)$, ascorbic acid concentration $\left(\mathrm{c}_{\mathrm{A}}\right)$ and refrigerated storage time $(\mathrm{t})$.
A quadratic polynomial regression model, Eq. (1), was assumed for predicting individual $\mathrm{Y}_{\mathrm{k}}$ response variables (Watada et al., 1987; Montgomery, 1991):

$\mathrm{Y}_{\mathrm{k}}=\mathrm{bk}_{\mathrm{o}}+\mathrm{bk}_{1} \cdot \mathrm{X}_{1}+\mathrm{bk}_{2} \cdot \mathrm{X}_{2}+\mathrm{bk}_{3} \cdot \mathrm{X}_{3}+\mathrm{bk}_{11} \cdot \mathrm{X}_{1}^{2}+\mathrm{bk}_{22} \cdot \mathrm{X}_{2}^{2}+$

$+\mathrm{bk}_{33} \cdot \mathrm{X}_{3}^{2}+\mathrm{bk}_{12} \cdot \mathrm{X}_{1} \mathrm{X}_{2}+\mathrm{bk}_{13} \cdot \mathrm{X}_{1} \mathrm{X}_{3}+\mathrm{bk}_{23} \cdot \mathrm{X}_{2} \cdot \mathrm{X}_{3}$

where $b k_{0}, \quad b k_{i}, \quad b k_{i i}$, and $b k_{i j}$ are regression coefficients and $X_{i}$ the coded independent variables, linearly related to $\mathrm{c}_{\mathrm{C}}, \mathrm{c}_{\mathrm{A}}$, and $\mathrm{t}$ (Table 1 ).

The factorial design described was used for samples packaged in mono-oriented polypropylene bags (OPP) and in low density polyethylene bags (LDPE) (29 runs for each type of packaging film).

\section{Spinach Preparation}

Spinach (Spinacia oleracea L., var. Hybrid 424) was obtained from a local farm near Santa $\mathrm{Fe}$ (Argentina). Outer, damaged and yellowed leaves, roots, and stems were removed. The remaining leaves were cut into $30 \mathrm{~mm} \times 40 \mathrm{~mm}$ pieces and washed for 2 min in cold water $\left(4-6^{\circ} \mathrm{C}\right)$ containing $120 \mathrm{mg} / \mathrm{L}$ available chlorine. Then they were rinsed with running tap water and dipped in citric acid and ascorbic acid solutions for $2 \mathrm{~min}$ as described in the experimental design. The spinach was centrifuged in a basket-type centrifuge at $540 \mathrm{rpm}$ for $3 \mathrm{~min}$. Fresh cut spinach samples $(70 \mathrm{~g})$ were placed in monooriented polypropylene bags $30 \mu \mathrm{m}$ thick, or in low density polyethylene bags $40 \mu \mathrm{m}$ thick, according to the experimental design. Gas transmission rates of OPP for $\mathrm{O}_{2}, \mathrm{CO}_{2}$, and water vapor were 2,000 $\mathrm{cm}^{3} / \mathrm{m}^{2} .24 \mathrm{~h}$.atm, $6,000-7,000 \mathrm{~cm}^{3} / \mathrm{m}^{2} .24 \mathrm{~h}$.atm (both at $23{ }^{\circ} \mathrm{C}$ and $1 \mathrm{~atm}$ ), and $3-5 \mathrm{~g} / \mathrm{m}^{2} .24 \mathrm{~h}$. (at $37{ }^{\circ} \mathrm{C}$ and $90 \% \mathrm{RH}$.), respectively. Gas transmission rates of LDPE for $\mathrm{O}_{2}, \mathrm{CO}_{2}$, and water vapor were 3,500-4,000 $\quad \mathrm{cm}^{3} / \mathrm{m}^{2} .24 \mathrm{~h} . \mathrm{atm}, \quad 12,000-15,000$ $\mathrm{cm}^{3} / \mathrm{m}^{2} .24 \mathrm{~h}$.atm (both at $23{ }^{\circ} \mathrm{C}$ and $1 \mathrm{~atm}$ ), and $10 \mathrm{~g} /$ $\mathrm{m}^{2} .24 \mathrm{~h}$. (at $37{ }^{\circ} \mathrm{C}$ and $90 \% \mathrm{RH}$.), respectively. Finally, the sealed bags were stored at $4.0{ }^{\circ} \mathrm{C}$ and $90 \% \mathrm{RH}$.

Table 1: Independent variables and their levels

\begin{tabular}{|l|c|c|c|c|}
\hline \multirow{2}{*}{ Independent variable } & \multirow{2}{*}{ Symbol } & \multicolumn{3}{|c|}{ Coded-variable levels $^{\mathbf{a}}$} \\
\cline { 3 - 5 } & & $\mathbf{- 1}$ & $\mathbf{0}$ & $\mathbf{1}$ \\
\hline Concentration of citric acid (\%,w/v) & $\mathrm{X}_{1}$ & 0.00 & 0.50 & 1.00 \\
Concentration of ascorbic acid (\%, w/v) & $\mathrm{X}_{2}$ & 0.00 & 0.50 & 1.00 \\
Time (day) & $\mathrm{X}_{3}$ & 0 & 7 & 14 \\
\hline
\end{tabular}

${ }^{\mathrm{a}}$ Coding equations: $\mathrm{X}_{1}=\left(\mathrm{c}_{\mathrm{C}}-0.50\right) / 0.50 ; \mathrm{X}_{2}=\left(\mathrm{c}_{\mathrm{A}}-0.50\right) / 0.50 ; \mathrm{X}_{3}=(\mathrm{t}-7) / 14$ 


\section{Microbiological Analysis}

Shredded spinach $(10 \mathrm{~g})$ was mixed with $90 \mathrm{~mL}$ $0.1 \%$ peptone water and homogenized with a stomacher for $2 \mathrm{~min}$. Further decimal dilutions, as required, were prepared with the same diluent and plated, in duplicate, on PCA and incubated during 48 $\mathrm{hr}$ at $30{ }^{\circ} \mathrm{C}$. Viable counts were reported as $\log$ $\mathrm{CFU} / \mathrm{g}$ (FAM).

\section{Sensory Analysis}

A trained quantitative descriptive panel was required to evaluate sensory quality attributes of spinach samples. The judges indicated their perception of the intensity of each quality attribute on a $100 \mathrm{~mm}$ unstructured line, with anchored terms located $10 \mathrm{~mm}$ from either end. They scored the perceived intensity of each descriptor by placing a vertical line across the unstructured scale line. Quantitation was accomplished by measuring the distance from the left end (0.00) to the vertical line, reporting measurements in $\mathrm{cm}$. The anchored terms were indicated from left to right as severe to none for off-odors, very poor to excellent for general appearance, very severe to none for wilting and browning, and yellow to dark green for color. Larger numbers on these scales represented higher quality for all attributes (Pirovani et al., 1997). The panelists evaluated development of off-odor, general appearance, wilting, browning, and color of fresh-cut spinach on each testing day.

\section{Statistical Analysis}

All data were submitted to analysis of variance to determine the effect of $\mathrm{c}_{\mathrm{C}}\left(\mathrm{X}_{1}\right), \mathrm{c}_{\mathrm{A}}\left(\mathrm{X}_{2}\right), \mathrm{t}\left(\mathrm{X}_{3}\right)$, and type of packaging film $\left(\mathrm{X}_{4}\right)$. STATGRAPHICS Plus was used to fit the experimental data to the secondorder polynomial equations, to obtain the coefficients of the equations, for regression analyses, and for analyses of variance. Response surfaces and contour plots were developed using the fitted quadratic polynomial equations obtained.

\section{RESULTS AND DISCUSSION}

The multifactor ANOVA indicated that storage time affected $(\mathrm{p} \leq 0.001)$ all sensory attributes studied and total microbial counts. Type of packaging film $\left(\mathrm{X}_{4}\right)$ only influenced $(\mathrm{p} \leq 0.001)$ development of off-odor of fresh-cut spinach. The multifactor ANOVA also indicated that type of packaging film and the corresponding interaction terms of this factor $\left(\mathrm{X}_{1} \cdot \mathrm{X}_{4}, \mathrm{X}_{2} \cdot \mathrm{X}_{4}, \mathrm{X}_{3} \cdot \mathrm{X}_{4}\right)$ had no effect $(p>0.05)$ on the visual sensory attributes and mesophilic aerobic population. Thus, the effect of $\mathrm{c}_{\mathrm{C}}$, $\mathrm{c}_{\mathrm{A}}$, and $\mathrm{t}$ on visual sensory attributes and microbiological counts for both types of packaging film was modeled as a whole (Montgomery, 1991).

Di Pentima et al. (1996) studied sensory quality of ready-to-use broccoli, whole spinach leaves and asparagus packaged in different plastic films, stored at $4{ }^{\circ} \mathrm{C}$. They also found no differences in general appearance, color, browning, and wilting in samples packaged in different types of films. However, development of off-odor was significantly different depending on the film used, with higher values for the film with lower permeability.

The ANOVA analyses of regression models indicated the models were highly significant $(\mathrm{p} \leq$ $0.001)$, exhibiting no significant lack of fit ( $p>$ $0.05)$. The coefficients of determination $\left(\mathrm{R}^{2}\right)$, explaining the variability of experimental data, were satisfactory. Based on all these tests, the prediction models were accepted. The regression coefficients of the fitted models are presented in Table 2.

Shelf life of the product must exceed the minimum distribution time required from the processor to the consumer to allow a reasonable period for home storage and use. This shelf life is defined as the time period that a product can be expected to maintain a predetermined level of quality under specified storage conditions (Shewfelt, 1986). Considering that fresh-cut vegetables must maintain their fresh-like quality and the limit of mesophilic aerobic population proposed by the French legislation at the end of the consumption stage, the shelf life was defined as the time of refrigerated storage at which any one of the sensory attributes scored below 7 or when the microbiological counts exceeded 5.10 $\mathrm{CFU} / \mathrm{g}$ (Anónimo, 1989; Pirovani et al., 1997).

The shelf life of a whole product at any given temperature is determined by the mechanism in any component which proceeds fastest and thus causes the shortest life. A major question for fresh-cut vegetables is whether sensory spoilage, as a result of chemical or biochemical reactions, or growth of spoilage organisms determine the shelf life. To answer this question, in this work, the shelf life of fresh-cut spinach was determined by superimposing the contour plots of each sensory attribute over the contour plot of mesophilic aerobic count for the selected criteria. Contour plots represented lines of equal sensory score or FAM as a function of time and ascorbic acid concentration for $\mathrm{c}_{\mathrm{C}}=0.50 \%$.

The shaded areas in Figures 1, 2, and 3 show the commercialization period for spinach samples, which 
satisfies the following conditions simultaneously: sensory attribute scores $\geq 7$ and FAM $\leq 7.70$.

It was found that wilting, browning, and color scores were always higher than 7 when $\mathrm{FAM}=7.70$. Therefore, these visual attributes did not determine the shelf life of fresh-cut spinach packaged in OPP or LDPE bags (Figure 1).

The off-odor score of fresh-cut spinach packaged in OPP bags decreased faster than the off-odor score of samples packaged in LDPE bags and decreased to 7 before the mesophilic aerobic population reached the limit value of 7.70. (Figure 2). Therefore, development of off-odor was the attribute that limited shelf life of fresh-cut spinach packaged in OPP bags up to 6 days (Figure 2a).

It was found that the general appearance score could decrease to 7 before FAM $=7.70$ for samples packaged in LDPE. For a chemical treatment of $\mathrm{c}_{\mathrm{A}} \geq$
$0.94 \%$ and $\mathrm{c}_{\mathrm{C}}=0.50 \%$ (Figure $\left.3 \mathrm{a}\right)$ or $\mathrm{c}_{\mathrm{C}}=1.00 \%, \mathrm{c}_{\mathrm{A}}$ $\geq 0.71 \%$ (Figure $3 \mathrm{~b}$ ), general appearance is the attribute that conditioned shelf life of fresh-cut spinach packaged in LDPE bags up to 8 days.

Pirovani et al. (1997) also found that the failure attribute that conditioned the shelf life of minimally processed cabbage could be different depending on the packaging film used.

When deciding whether to buy a particular commodity, consumers evaluate fresh-cut vegetable quality by visual sensory attributes. Therefore, according to score ratings obtained for visual sensory attributes, some fresh-cut spinach samples could be considered suitable for commercial sale after 14 days of storage. Thus, with no obvious signs of spoilage, mesophilic aerobic microorganisms might be present at high concentrations, without anything to warn consumers of the danger.

Table 2: Regression coefficients of the second-order polynomial equations

\begin{tabular}{|c|c|c|c|c|c|c|c|}
\hline Coefficients & FAM & $\begin{array}{c}\text { Off- odor } \\
\text { OPP }\end{array}$ & $\begin{array}{c}\text { Off- odor } \\
\text { LDPE }\end{array}$ & $\begin{array}{c}\text { General } \\
\text { Appearance }\end{array}$ & Wilting & Browning & Color \\
\hline $\mathrm{b}_{\mathrm{o}}$ & 7.752 & 6.941 & 8.266 & 8.025 & 8.191 & 7.968 & 8.136 \\
$\mathrm{~b}_{1}$ & -0.523 & -0.014 & -0.144 & -0.378 & -0.176 & -0.282 & -0.089 \\
$\mathrm{~b}_{2}$ & -0.316 & -0.092 & -0.391 & -0.564 & -0.180 & -0.445 & -0.157 \\
$\mathrm{~b}_{3}$ & 3.156 & -2.211 & -0.787 & -1.380 & -0.860 & -0.986 & -1.023 \\
$\mathrm{~b}_{11}$ & 0.201 & -0.480 & -0.051 & 0.0396 & 0.078 & -0.0124 & -0.033 \\
$\mathrm{~b}_{22}$ & -0.0397 & -0.314 & 0.109 & -0.485 & -0.187 & -0.285 & 0.036 \\
$\mathrm{~b}_{33}$ & 0.946 & 0.278 & -0.191 & -0.363 & -0.133 & 0.00087 & -0.317 \\
$\mathrm{~b}_{12}$ & 0.122 & 0.307 & -0.303 & -0.301 & 0.0113 & -0.054 & -0.185 \\
$\mathrm{~b}_{13}$ & -0.096 & 0.064 & 0.0025 & -0.325 & -0.1496 & -0.097 & -0.191 \\
$\mathrm{~b}_{23}$ & -0.127 & -0.042 & -0.228 & -0.488 & -0.155 & -0.292 & -0.3198 \\
\hline
\end{tabular}

Wilting

$\mathrm{c}_{\mathrm{C}}=0.50 \%$

Time (day)

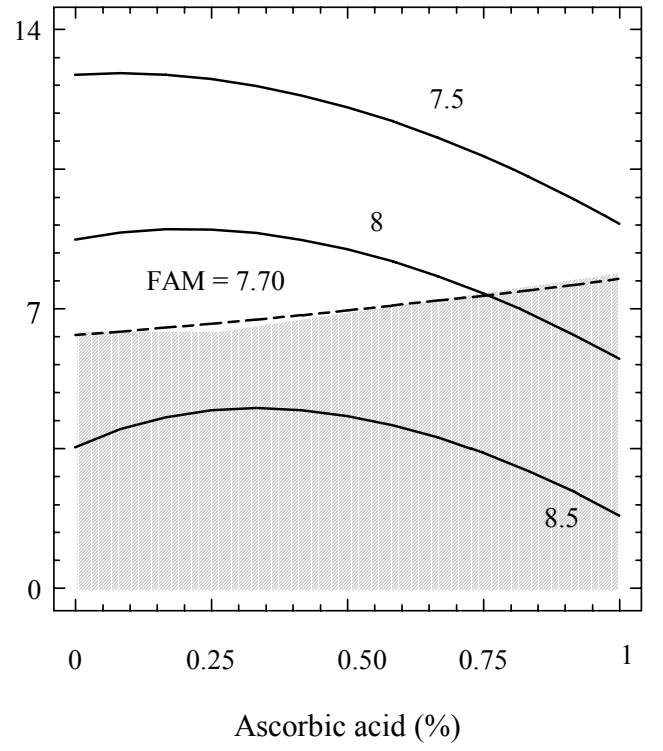


Browning

$\mathrm{c}_{\mathrm{C}}=0.50 \%$

Time (day)

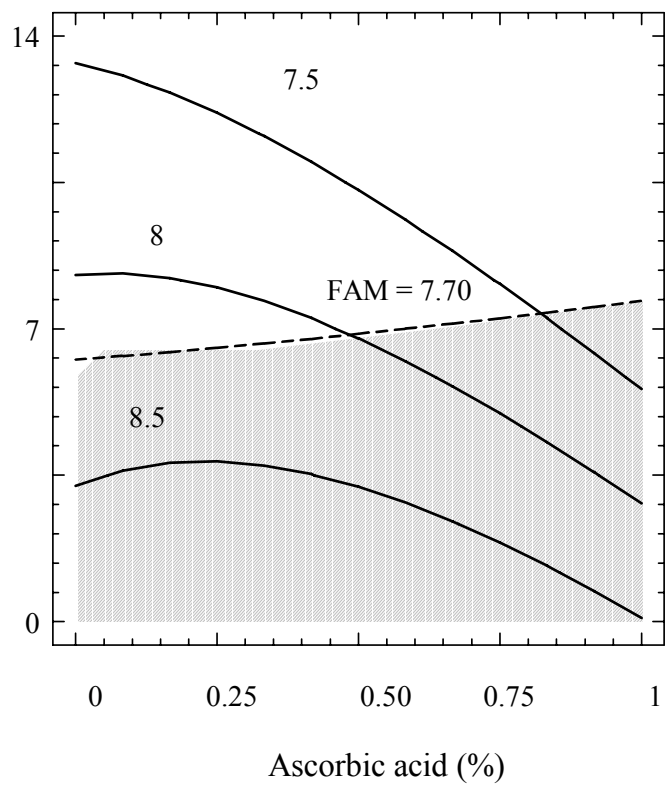

Color

$\mathrm{c}_{\mathrm{C}}=0.50 \%$

Time (day)

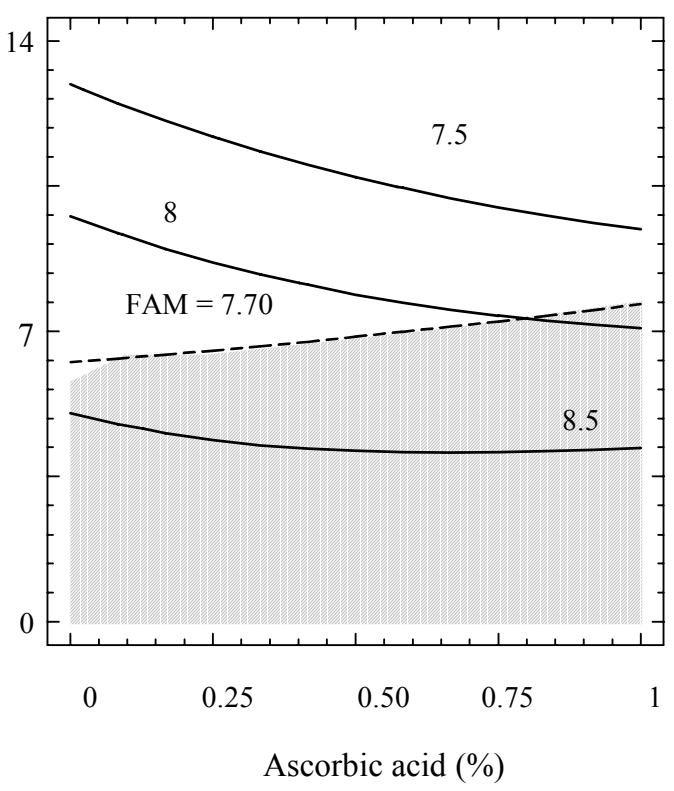

Figure 1: Contour plots of wilting, browning, and color superimposed over the contour plot of mesophilic aerobic counts (FAM) at 7.70

(a) Off-odor OPP

$\mathrm{c}_{\mathrm{C}}=0.50 \%$

Time (day)

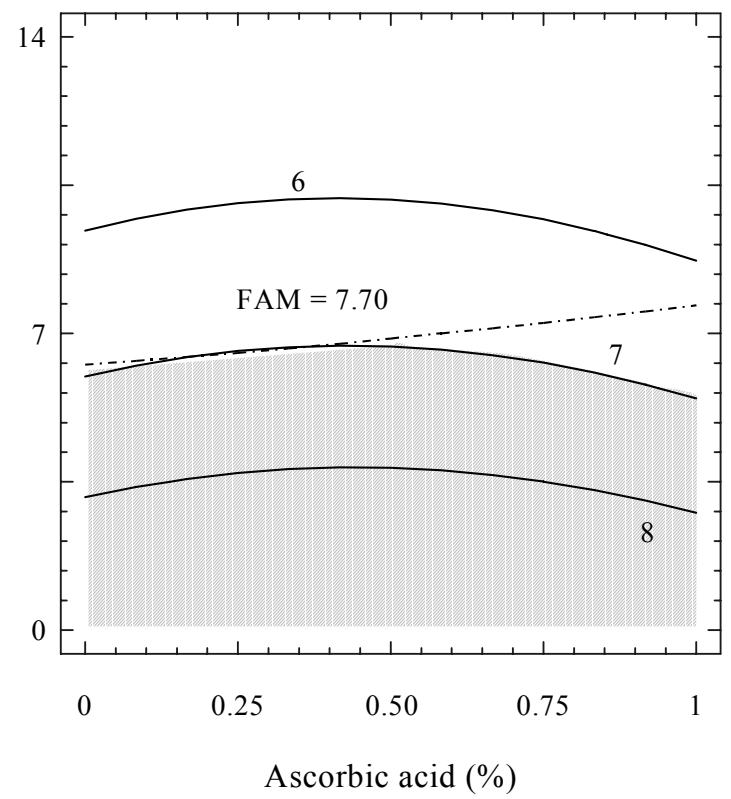

(b) Off-odor LDPE $\mathrm{c}_{\mathrm{C}}=0.50 \%$

Time (day)

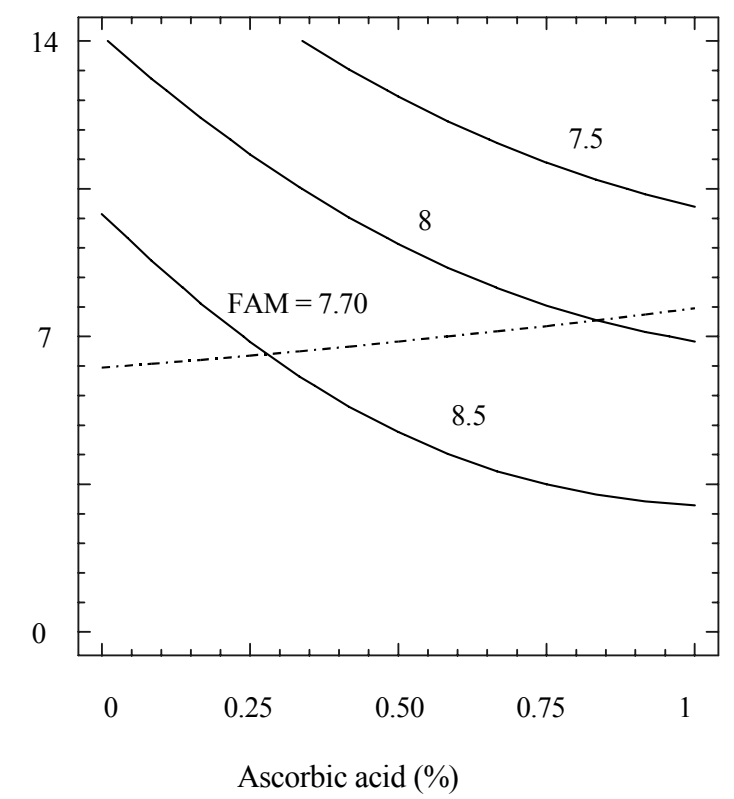

Figure 2: Contour plots of development of off-odor superimposed over the contour plot of mesophilic aerobic counts (FAM) at 7.70 
(a) General appearance

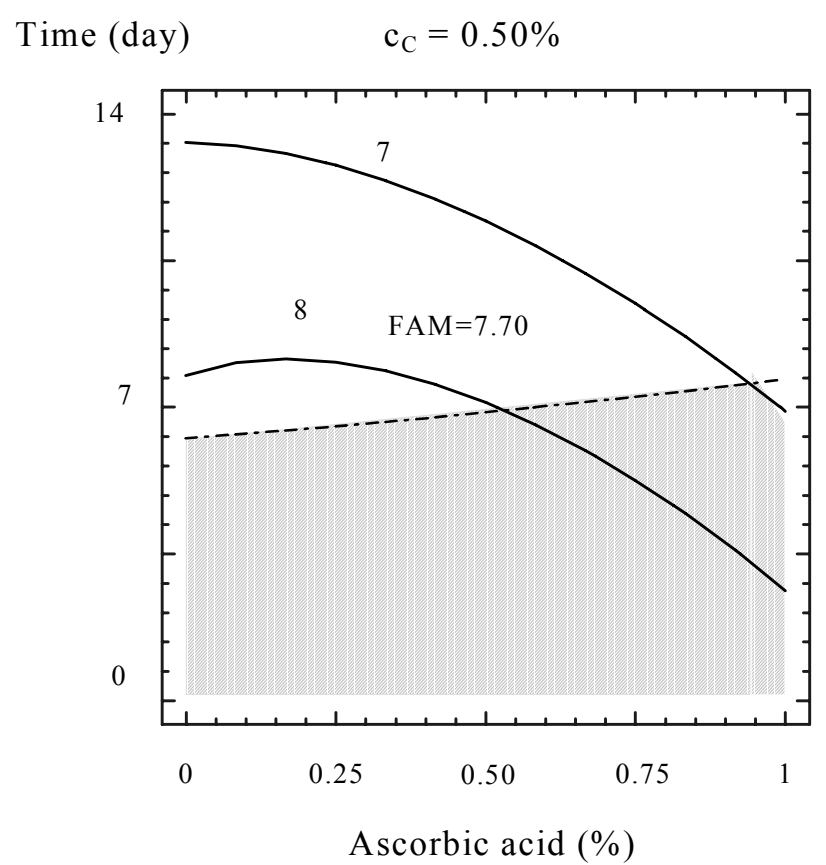

(b) General appearance
Time (day)
$\mathrm{c}_{\mathrm{C}}=1.00 \%$

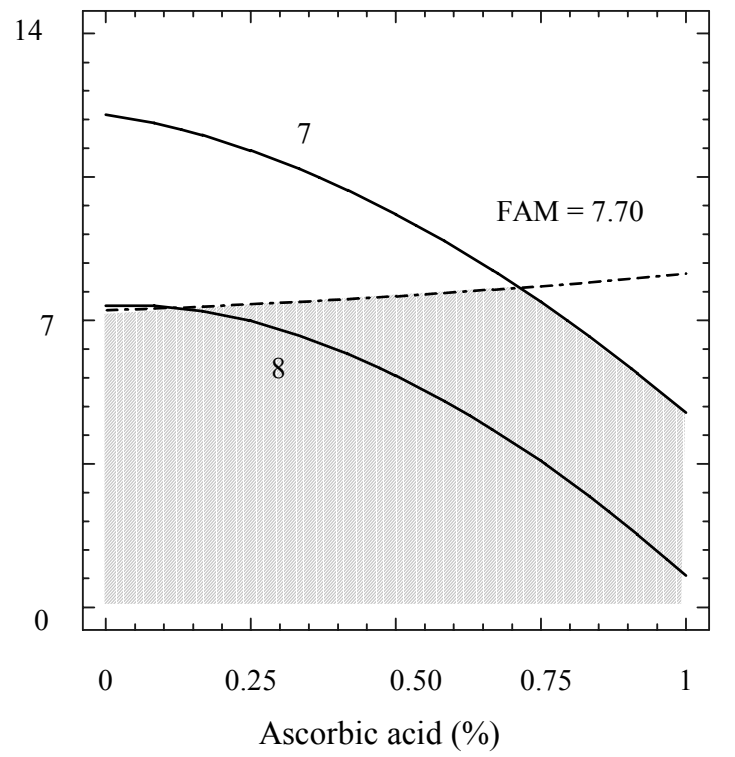

Figure 3: Contour plots of general appearance superimposed over the contour plot of mesophilic aerobic counts (FAM) at 7.70 


\section{CONCLUSIONS}

Type of packaging film only influenced development of off-odor $(p \leq 0.001)$ and had no effect on visual sensory attributes or microbiological counts $(\mathrm{p}>0.05)$. Development of off-odor was the attribute that limited shelf life of fresh-cut spinach packaged in OPP bags. On the other hand, the shelf life of samples packaged in LDPE bags was dependent on a decrease in general appearance or an increase in microbiological counts, depending on the chemical treatment used.

For fresh-cut spinach stored at $4{ }^{\circ} \mathrm{C}$ and $90 \% \mathrm{HR}$ a level of quality between excellent and good can be maintained for eight days using LDPE bags or for six days using OPP bags.

\section{ACKNOWLEDGMENTS}

We thank Universidad Nacional del Litoral (Santa Fe - Argentina) for financial support under Project CAI+D. We gratefully acknowledge the technical assistance of M. S. Salsi and M.A. Moguilevsky (microbiological analysis). We also extend our gratitude to the staff of the Instituto de Tecnología de Alimentos, who participated in the sensory evaluation.

\section{REFERENCES}

Anónimo. (1989). Dispositions concernant le produit fini. En Guide de Bonnes Practiques Hygiéniques concernant les produits végétaux dits de $1 \mathrm{a} \mathrm{IV}^{\mathrm{e}}$ Gamme. Extrait du bulletin officiel de la République Francaisse. Ctifl, París, Francia.

Brecht, J.K. (1995). Physiology of lightly processed fruits and vegetables. Hortscience, 30(1):18-22.
Castañer M., Gil M. I., Artes F., and TomasBarberan F. A. (1996). Inhibition of browning of harvested head lettuce. J. Food Sci. 61(2):314-316.

Di Pentima, J.H., Güemes, D.R., Pirovani, M.E., and Piagentini, A.M. (1996). Estudio del comportamiento de vegetales listos para usar, envasados con diferentes láminas plásticas. La Alimentación Latinoamericana, 213, 46-50.

Huxsoll, C.C. and Bolin, H.R. (1989). Processing and distribution alternatives for minimally processed fruits and vegetables. Food Technol., 43 (2), 124-128.

Langdon, T.T. (1987). Preventing of browning in fresh prepared potatoes without the use of sulfiting agents. Food Technol., 41(5), 64-67.

Montgomery, D.C. (1991). Diseño y análisis de experimentos. 3rd Ed México: Grupo Editorial Iberoamérica.

Pirovani, M.E., Güemes, D.R., Piagentini, A.M., and Di Pentima, J.H. (1997). Storage quality of minimally processed cabbage packaged in plastic films. J. Food Quality, 20(5), 381-389.

Schlimme, D.V. and Rooney, M.L. (1994). Packaging of minimally processed fruits and vegetables. In: Wiley, RC, ed. Minimally Processed Refrigerated Fruits and Vegetables. New York: Chapman \& Hall, Inc., pp.135-182.

Shewfelt, R.L. (1986). Postharvest treatment for extending the shelf life of fruits and vegetables. Food Technol., 46 (5), 70-80/89.

Watada, A.E., Kim, S.D., Kim, K.S., and Harris, T.C. (1987). Quality of green beans, bell peppers and spinach stored in polyethylene bags. J. Food Sci., 52(6), 1637-1641.

Wiley, R.C. (1994). Preservation methods for minimally processed refrigerated fruits and vegetables. In: Wiley, R.C., ed. Minimally Processed Refrigerated Fruits and Vegetables. New York: Chapman \& Hall, Inc., pp. 66-134. 